\title{
Research on the Training Mode of Spatial Thinking about Landscape
}

\author{
Design \\ Ying $\mathrm{Gao}^{1 \mathrm{a}}$, Jian Tang${ }^{1}$, Mo $\mathrm{Li}^{2}$, Shenjian $\mathrm{Hu}^{1}$ \\ ${ }^{1}$ School of Architecture and Fine Art, Dalian University of Technology \\ 2 City college, Dalian University of Technology \\ a505896946@qq.com
}

Key words: Landscape Architecture Space Design Reformation of curriculum Experimental

\begin{abstract}
With the ascendant of Landscape design in China, more and more people pay attention to the pattern of cultivating landscape professionals. In the paper, on account of Landscape major students are lack of "space design" creative ability, we try to reform our teaching methods experimentally in space design with teaching experience. By analysis and evaluation of various stage curriculums, trying different methods in different grades students to cultivating the sense of space. In the limited hours, by integration of the teaching task, enable students to develop from low grade on design thinking with the perspective of three-dimensional mode of thinking. The "space design" should better go throughout the whole design cycle.
\end{abstract}

\section{Background}

In order to adapt to the change of social landscape talent demand pattern, various colleges and universities have opened landscape design professional in China. At present, the opening of this professional institutions are mainly concentrated in the landscape architecture, art college and architecture college. Courses setting of Landscape professional in different colleges and backgrounds is vary considerably in weight distribution, teachers also have a certain tendency. Therefore, the landscape Therefore, the expertise and characteristics of the students from different colleges are in different style. And from the point of view of the information feedback from the design company, the students from architecture colleges have advantages in architecture space, position sense, stereo sense, understanding of the region, location, height, height, elevation and building materials.

\subsection{Situation of Teaching}

Take example as environment design professional of Dalian University of Technology(Dlut), landscape design courses are started from grade two, however, there are not enough courses about design principle for students before the opening of design courses. Composition courses opened in grade one aimed to change the thinking of students from two dimensional to three dimensional slowly, But these courses did not achieve the desired teaching objectives, and follow-up of the design class seriously "out of touch." Thus, the basic space design course is relatively weak, resulting in the design of the teaching of the course encountered great difficulties.

\subsection{Misunderstanding of cognition}

As is known to all, the building space is surrounded by 6 surfaces, and the focus of landscape design is mainly on the ground plane. So many people in the narrow sense of the landscape design as a simple two-dimensional structure, while ignoring the other vertical and top surface of the comprehensive consideration. Which leads that students spend a lot of time in the design of the plane, focus on whether it looks good. In the landscape design, many students repeatedly portrays a 
general plan of strong sense. Then to find the reference pictures, or to pull high the trees based on the plane to form vertical design. From the author's practical experience, a large number of students are accustomed to this kind of design method, and neglect the necessity and importance of space design in landscape design

\section{The necessity of spatial creativity in landscape design}

"Sense of space" is very important for a good landscape architect. As mentioned above, the students graduated from architecture colleges of landscape design have advantages in the program design. Because in this kind of college, the architecture specialized class occupies the very big proportion, the curriculum is paid enough attention to the space construction, the student's spatial design ability can be strengthened accordingly. In view of the above situation, the author believes that it is very necessary to strengthen the "space creative" in the course of landscape design. How to maximize the use of limited hours to cultivate students' spatial creativity is an urgent problem to be solved.

But how to try new experimental methods in the curriculum content, the introduction of new teaching mode in the teaching mode, establishing a connection in the longitudinal direction of curriculum, the space design thinking throughout, this is the author in the study to the problems in teaching.

\section{Discussion on the Mode of Space Design Teaching}

\section{1 space composition transformation: Morphological to the spatial}

The teaching purpose of space composition is to cultivate students' ability to analyze simple spatial thinking and to lay the foundation for the next step of cognitive complexity. At present a lot of stereoscopic teaching content followed the Academy of fine arts, will focus on shaping the form, This is only the creation of form which led to the subsequent design courses can not be formed with a good butt. How to build "virtual" shape is more practical significance for students. To a certain extent, space is obtained through constant enclosure and definition. The traditional space composition training is not to achieve the purpose of this training, students still did not know how to apply the knowledge to the design of the following, and the basic concept of "space design" is still not formed.

In order to let students understand the basic principles of space, improve the spatial awareness, cultivate the most elementary space creativity and divergent thinking of innovative ability, change the mechanical practice mode and thinking mode, combine the infinite possibility of virtual space creation mode into space composition class. Students make use of simple geometry model, just like building blocks, try to a variety of possible enclosure. Put emphasis on the characteristics of this space is what kind and how to attract other people. This allows students to return to the original creativity of the training model is more easy to stimulate their imagination. This stage is independent, free to play the creation of time, the mind of the basic information into unlimited information, so that the basic knowledge of the form of cognitive ability and imagination thinking unlimited expansion.

\subsection{Digital construction of classical space works}

The basic course of landscape design is always a very important link in teaching. How to make the landscape design simple and effective primary education, is a challenging topic. It is necessary that students must analyze classic case before creation. Many colleges have opened basic course with analysis of famous works. But we found that the traditional pattern of training did not achieve the desired results. Because the students are not familiar with the drawings of architecture, so it is very difficult for them to cognize the meaning. which leads students just to copy the works without reading the drawings. Originally a "looking for - Identification - Analysis - reproduction" of the 
process into a simple and meaningless copy, pure drawing. Even if the final submission of the drawings to be detailed, it does not mean that students grasp the essence of the classic case of space design.

Therefore, the author believes that the teacher should lead the students to make model of spatial cognition, the whole process of analysis and interpretation of a good case in the stage of teaching, let the students get the most intuitive perception. At present, the other very convenient method is to make 3D dynamic model. Because the author is also responsible for the teaching task of computer aided design, the research direction includes digital technology, virtual reality and so on.

Based on this, students will analyze typical works through digital input, build three-dimensional model, and then guide the students for the work of the space design of the essence of the space sequence of experience, and repeated comparison.

Take an example, the author have been assigned to design the dwelling landscape to be demonstrated by $\mathrm{Vr}$ to students. Then students to experience the scale of space of the dwelling, Students' perception of space is transformed from two-dimensional to three-dimensional space easily. Finally, let the students feel their own profound spatial analysis by drawing. The drawing itself is not important at this time, the space concept formed in the mind is the purpose of this time.

\subsection{Investigation and measurement}

Investigation and measurement are the most direct and effective methods in real cognitive space. Through personal experience will have a further understanding of the vertical dimension, the spatial scale has a more intuitive feeling, field analysis, understanding of the objective entity. The author select similar size, the same nature of the case organization everyone to visit in each design class for different design topics to select. In the process, students records the visit experience through the machine and other tools on the sketch book, then generate research report and the organization of collective evaluation lastly. In addition, also allows students to spontaneously form a research group, select the campus environment around the field measurements. The process is: cognitive - Measurement - Quantitative - drawing expression - Analysis - Evaluation - improvement. Particular emphasis on the vertical design, analysis of the scene drawing, help students to understand the space, more help to stimulate the creative thinking of students

\subsection{Preliminary model;}

The development of digital technology brings convenience to the design, but also has some disadvantages. The drawing tool design course early is basically a drawing board, a T-square, etc., when the third began to contact the computer graphic, learning Auto CAD, not to mention the 3D input computer, so only through Handmade model to scrutiny of volume and space, each of which is the design course must complete the tasks. With the popularization of computers, various software functions are growing stronger, so now the students behind the traditional Handmade model lost, many students from the second grade just contact design, the use of computer graphics, a strong dependence on computer input. Students have no chance to try and make the model during the whole study period. The author thinks that the hand making model is as important to a designer as it is to master the drawing technology, the model has an important influence on the space of the whole analysis, which can not be ignored. The use of simple materials, according to their own space for the imagination of thinking and logical analysis of the design and production of the model, for beginners who have a strong space for the design of intuitive, participatory and experientialin the training, the best students will design a model expression of thinking and space constitute the "concept" model, rather than focus on a detail of the carving, to make the difference between a model and model company. 


\section{Conclusion}

Can the teaching reform of the course form, trying to keep the topic opening, experiment and research, any single teaching mode can provide complete and effective experience, improve the teaching efficiency through efficient teaching mode, to explain all the possible design principle, form and value, to enable students to obtain knowledge and deal with problems the means, and the concept of professional confidence. As the beginning of garden design, space design emphasizes the introduction of design methods and the continuity of the course. The goal should be set at every stage.

\section{Acknowledgement}

Supported by the Fundamental Research Funds for the Central Universities (Grant No. DUT16RW105)

Supported by the Education and Teaching Reform Fund of Dalian University of Technology (Grant No. ZD2016012)

Our major as higher education to the application of the transformation of the development of the pilot professional

\section{References}

[1] GaoYing, LuanYiFei, TangJian, Study on the Construction of Teaching System about

Landscape Design Course of Environmental Art Specialty of Technological Universities, Journal of Human Settlements in West China. 2015(04): 11-14

[2] GaoYing, FanYue, HuShenJian, Explore the Teaching Means of Existing Housing Environment Regeneration Design, Journal of Community. 2016 (10):138-141

J. van der Geer, J.A.J. Hanraads, R.A. Lupton, The art of writing a scientific article, J. Sci. Commun. 163 (2000) 51-59. 